\title{
A Model of a Localized Cross-Border E-Commerce
}

\author{
Abbas Asosheh ${ }^{1}$, Hadi Shahidi-Nejad ${ }^{2}$, Hourieh Khodkari ${ }^{3}$ \\ ${ }^{1}$ Faculty of Engineering, Tarbiat Modares University, Tehran, Iran; ${ }^{2}$ Department of Information Technology, Tarbiat Modares Uni- \\ versity, Tehran, Iran; ${ }^{3}$ Faculty of Engineering, University of Tehran, Tehran, Iran. \\ Email: \{asosheh, shahidinejad\}@modares.ac.ir, khodkari@ut.ac.ir
}

Received February $25^{\text {th }}, 2012$; revised March $12^{\text {th }}, 2012$; accepted March $26^{\text {th }}, 2012$

\begin{abstract}
By the explosive growth of B2B e-commerce transactions in international supply chains and the rapid increase of business documents in Iran's cross-border trading, effective management of trade processes over borders is vital in B2B e-commerce systems. Structure of the localized model in this paper is based on three major layers of a B2B e-commerce infrastructure, which are messaging layer, business process layer and content layer. For each of these layers proper standards and solutions are chosen due to Iran's e-commerce requirements. As it is needed to move smoothly towards electronic documents in Iran, UNedocs standard is suggested to support the contents of both paper and electronic documents. The verification of the suggested model is done by presenting a four phase scenario through case study method. The localized model in this paper tries to make a strategic view of business documents exchange in trade processes, and getting closer to the key target of regional single windows establishment in global trade e-supply chains.
\end{abstract}

Keywords: E-Commerce; Cross-Border Trade; Electronic Document Management; International Supply Chain

\section{Introduction}

Electronic commerce is about buying and selling products or services over electronic systems like internet and other networks. The term B2B (Business-to-Business) describes commerce transactions between businesses, such as between a manufacturer and a wholesaler, or between a wholesaler and a retailer. In this paper the research focus is on the communication between traders in two different countries. Today one of the main targets of the world trade organization is to establish regional single windows which can increase the trade facilitation in different parts of world. Establishing a regional single window needs cross border gateways that can exchange trade documents efficiently. So first, the key necessity of managing the simplified documents over borders is to move toward national single windows. After that, the regional single windows can authorize the communication between countries.

E-commerce models are studied based on the three major logical layers. These three layers are messaging layer, business process layer and content layer [1,2].

Generally the localized model in this paper is a way to automate the process of exchanging trading documents. This can be a step through establishing the National single window of Iran and then with the more interoperability between the East Asian and Middle Eastern countries a regional single window can be improved in the future.
In this paper the second section is discussed basic concepts and standards required to introduce the crossborder B2B model in international supply chains. The third section is assigned to introduce the scope of the model and its components functionality in a big picture schema. The forth section discusses the model localization over B2B transaction layers, and finally the paper in concluded.

\section{Background}

In this section, besides, having a look at B2B e-commerce in Iran, the background concepts such as standards and reference models which are being used in localization of the B2B e-commerce cross border model are discussed.

\subsection{B2B E-Commerce in Iran}

Today the performance of the trade processes in Iran is a key trade success point. Iran has long borders with many of the countries in the region and its import and export processes can be done over road, rail, sea and air ways. So the central and strategic role of this country makes it a key trade point of goods transit in the Asia and Middle East region.

Today, almost all of trade processes in Iran customs are done through paper forms, and the electronic services given by the ministry of commerce are restricted to the 
merchants who trade inside the country. The introduced model tries to simplify the process of exchanging electronic documents in the cross-border e-supply chains of Iran trading. Here some of the systems which give the electronic services by the ministry of commerce in Iran are mentioned:

- Importation Order Management System.

- Trade Statistics System.

- Iran Code.

- Made In Iran.

These are the main electronic systems which are using today to facilitate trade processes in Iran. The systems are mentioned here as independent trade facilitators which can have interaction with the suggested model in this paper in the future.

Joining Iran to the world trade organization regarding the standardization of data elements and trade processes can be a good movement through improving regional single windows in Asia.

From the designing point of view, one of the main advantages of document data harmonization in Iran is the reduction of data elements of the forms. So they can be reused in different documents as much as possible. This makes the country ready for using any standard forms of data. So the localized cross-border model in B2B e-commerce can make the trade processes make faster and safer which is one of the necessities of Iran's trading today.

\subsection{Single Window}

The Single Window is a system, which enables single submission entry and Single and synchronous processing of data and information. These can help the system to make a key service which is so effective in shipping goods over the borders which is: A Single Decisionmaking point for customs release and clearance of cargo $[3,4]$.

It is needed to go through establishing a National single window in Iran to get closer to joining a regional single window.

\subsection{Buy-Ship-Pay Reference Model}

In order to understand the complexity of international trade, this simple model can make a clear view of the key elements of a trade transaction, and consequently to pro- perly compile the necessary trade facilitation measures. UN/CEFACT has set out this to model the international supply chain using an internationally accepted modeling technique to provide reference model, which gives a view of the international supply chain in its entirety [5].

A simple view of the international supply chain based on BSP model includes three main categories of processes which are buy, ship and pay, plus four types of roles such as customer, authority, intermediary and supplier (Figure 1).

As discussed above, the recommended measures, grouped into four categories, relate to the processes in this model.

- BUY - Covering all commercial activities related to the ordering of goods;

- SHIP-Covering all of the activities involved in the physical transfer of the goods, including official controls;

- PAY - Covering all of the activities involved in the payment for the goods $[5,6]$.

After classifying the main categories of roles and processes in a cross-border supply chain, it is needed to have a closer view at different types that each of these categories can support.

Different procedures and roles of the BSP model can be described by use case diagrams to show the relation between roles and processes. Some processes are related to identifying business partners or agreement establishment which is being separated regarding the scope of cross-border model (Figure 2).

\section{Model Introduction}

In this section the customized model in cross-border ecommerce is being introduced. The subsections include Model scope, main model components and their behavior over B2B transactions in different B2B transaction layers.

\subsection{Model Scope}

In this subsection the scope of the B2B cross border model regarding its roles and use cases is discussed.

Different levels of data integration exist which can be done to simplify the data sets. In this model the focus is on the international layer. Harmonizing data elements in

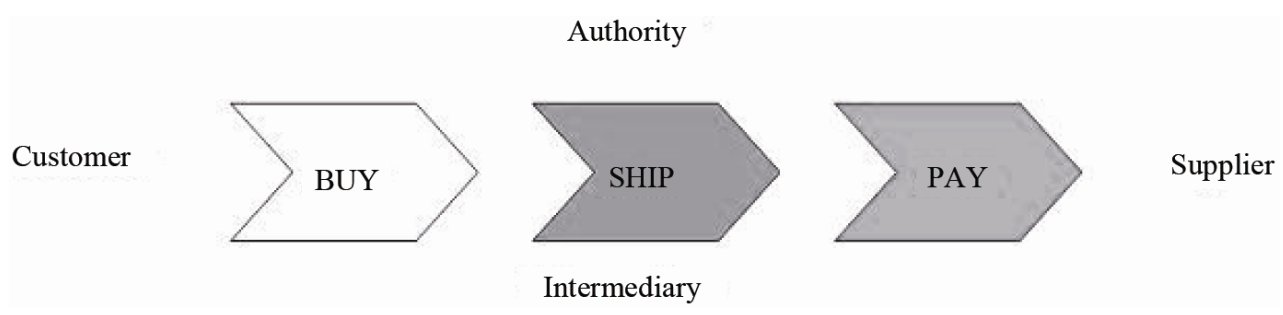

Figure 1. International supply chain [5]. 


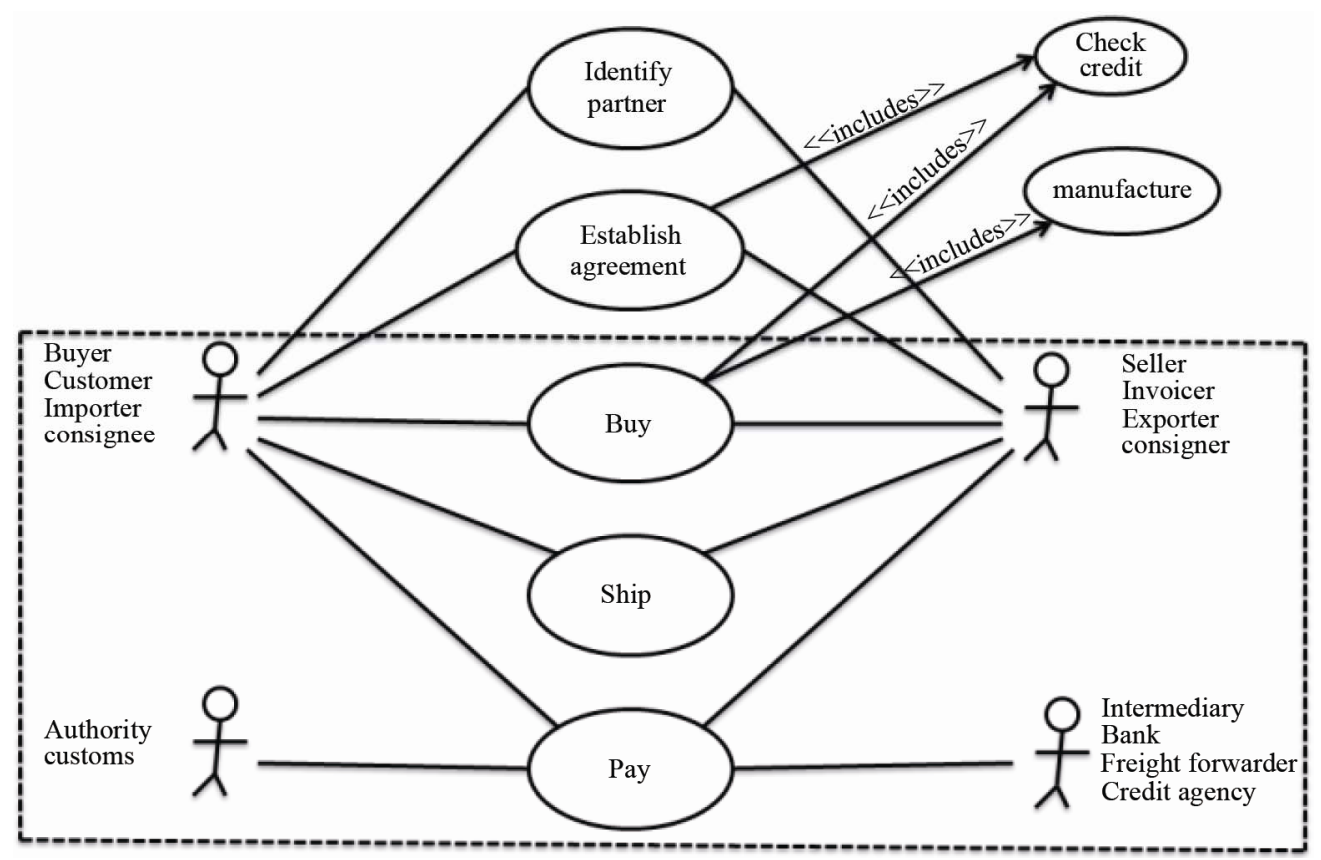

Figure 2. Roles and use cases in the BSP model [6].

the exchange process, leads to effective cross-border trade. Generally, the scope of the model in this paper is about international layer, so the main aim is to harmonize trading transaction in processes and content [7].

Based on the concept of data harmonization which is suggested in both sides of supply chain; proper standards and solutions in analyzing the model can be chosen. These standards have to support the cross border transactions.

\subsection{Model Components}

The buy-ship-pay reference model discussed as a way to simplify the processes and eliminate unnecessary details of a trade scenario. UNedocs project is suggested to cluster and manage different documents. These standards are introduced as solutions to go through the single window policy.

First let's have a high level view of the components of the system while a cross-border communication is happening. In every side customs are placed which are leading to the national single window of the country. The documents in the National format are entering to the translator module which is changing the format of the documents to the standard UNedocs format [8]. Then it can go through a middleware to be declared more and finally the cross-border single windows is the last gateway. Every country can use this model form its own side to the exchange gateway (Figure 3).

\subsection{Certificate Authentication in the Model}

The relationship between CAs in this model is designed according to the basic types of PKI interoperability models. Based on the Iran's e-supply chain security requirements, it is needed to support the certificate authority by using the benefits of a variety of different relationship topologies. The architecture which is suggested here benefits the advantages of CA hierarchy model, certificate trust list and bridge CA interoperability models.

The benefits of this topology are:

- It will publish a trust list of national CAs. Those national CAs can retrieve the list themselves and are free to add and subtract CAs from the list and republish it to their government's users according to their own national preferences.

- It may also publish trust lists of CAs in particular sectors-for example, a list of CAs accredited to provide health certificates.

- It will cross-certify with each national CA and make that certificate available to other CAs to perform their own cross-certifications [9].

- It will provide a certificate authority center for giving approval to messages and forms while transferring through layers of the cross-border model. As it is mentioned above, the benefits of the hierarchy and modularity in this topology of CAs is improved Figure 4.

\section{Model Localization over B2B Layers}

In this section the components of the model are being discussed over three different layers of communication between B2B e-commerce systems. Each subsection shows the relationship between exporter, importer, customs, regional single window and the National single 


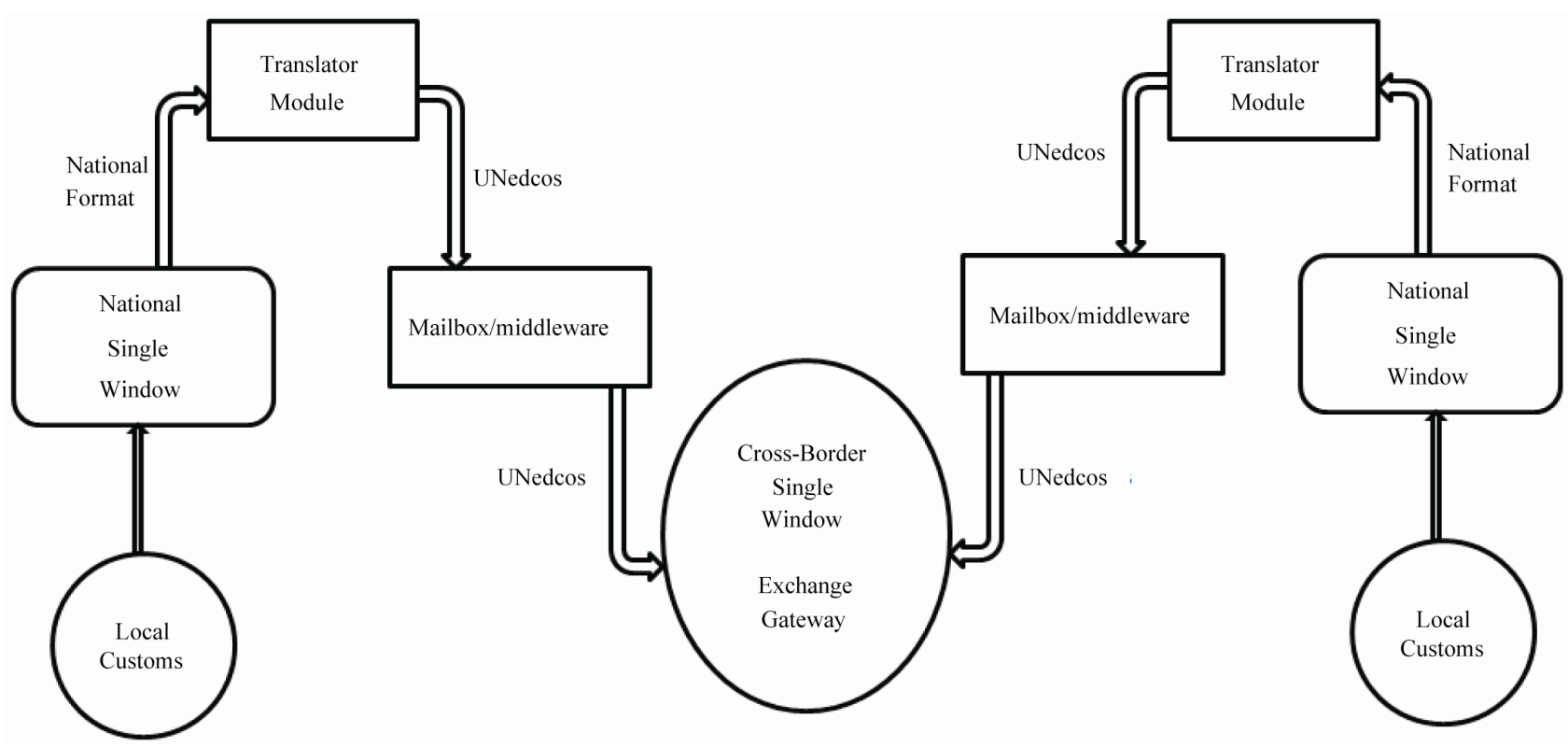

Figure 3. UNedocs and NSW in the big picture of the model.

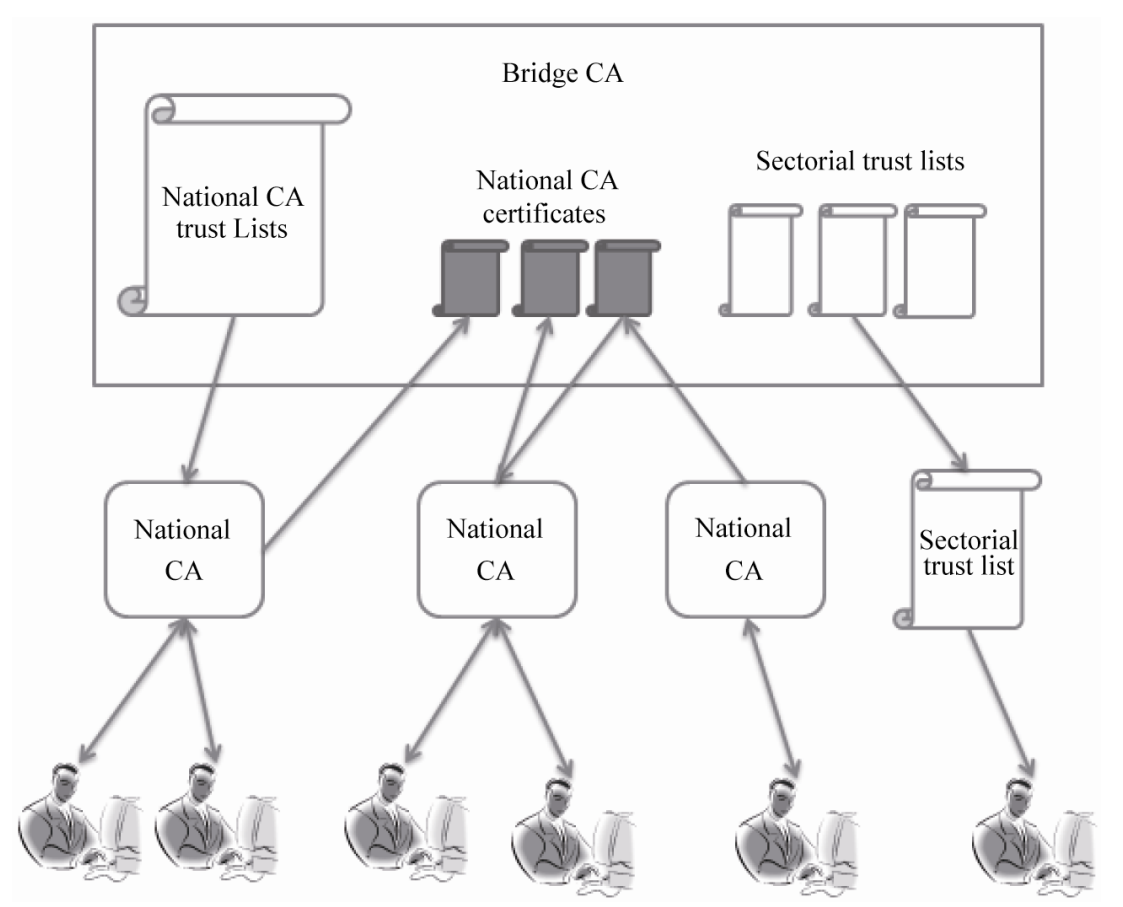

Figure 4. The CA interoperability topology in the model.

window in both sides of a trade transaction.

\subsection{Business Process Layer}

In the business process layers, the reference model and the UNedocs project are used to manage the electronic docs, but as a key step of project management first the exact scope of the transactions which are included in the suggested model must be described. According to what was mentioned about UNedocs, it is said that this project is mainly about the electronic documents but not about identifying the trading partner or the use cases which are about before contract.

While the relation between roles and processes are discussed, the scope of the model can be described more precisely in the business process layer. The scope of processes which are considered in the localized crossborder model of this paper can be seen inside the dotted line in Figure 2. 


\subsection{Messaging Layer}

The messaging layer is responsible to establish the communication session between components, and send the contents of the message to next layers of the components hierarchy [10]. The exporter and importer are considered as the first and last points of a communication line and single window systems in national and regional levels are responsible to process information and move them forward. The certificate authority component of the system is using to assure the acknowledgement of each message. The customs component is the authorization system of goods declarations. The layered architecture of the system is one of the main factors that increase the crossborder model's flexibility and extendibility. Messages mostly include approval of the forms in each level and updating the statues of certificate authority module in the structure of the cross-border model (Figure 5).

\subsection{Content Layer}

The content layer of the localized model deals with the documents, the objects which have to exchange through borders from exporter to importer and the opposite. One of the main challenges of this model is joining the B2B e-commerce system of Iran to a regional single window. As in Iran, paper documents are being used in the trading processes, so international standards to create and align documents which change the current documents readable for other partners in the international supply chains must be chosen. This layer is discussed from two aspects, first standards to design forms and second a solution for Exchanging forms through a unique gateway [11]. One more advantages of this model is data reusability. Same data elements in different forms can be detected and each layer can use the data elements which are entered in the system before [12,13].

The most important rule considered in this hierarchy is to send and receive documents via next layers of system, and every document submission in the model needs an acknowledgement message to guarantee the integrity of the communication system (Figure 6).

\subsection{Certificate Authorization}

As the PKI standards and the necessity of certificate authorization in B2B transactions were discussed before, finally, the role of certification authority center in relationship to other components of the cross-border e-commerce model is discussed.

It is clear that the main supervision roles in authorization are once before entering a form into the cycle and once after finishing work with that document to save it as a used code. The assigned numbers in the Figure 7, show the priority of tasks which happen in the scenario step by step. As the priority numbers show, in each country the National single windows receive forms and messages which are being sent through adaptors [14]. This will turn the content of each message in the "national format" that is readable for the regional single window which supervises the transaction. Certification authority checks the forms number unique and makes it easier to trace each trade transaction (Figure 7).

Based on the implementation point of view, the localized model is not depended on particular software or hardware infrastructure. By the use of XML technology

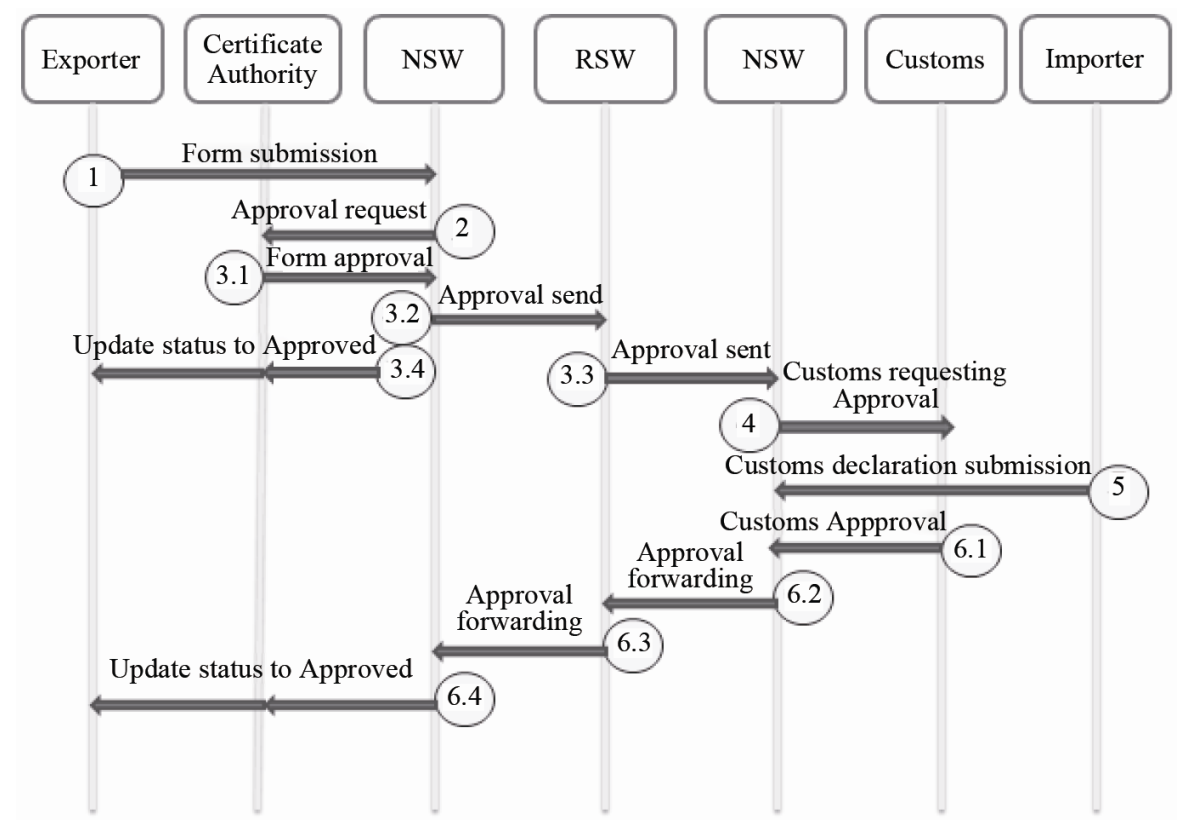

Figure 5. Messaging layer in the model. 


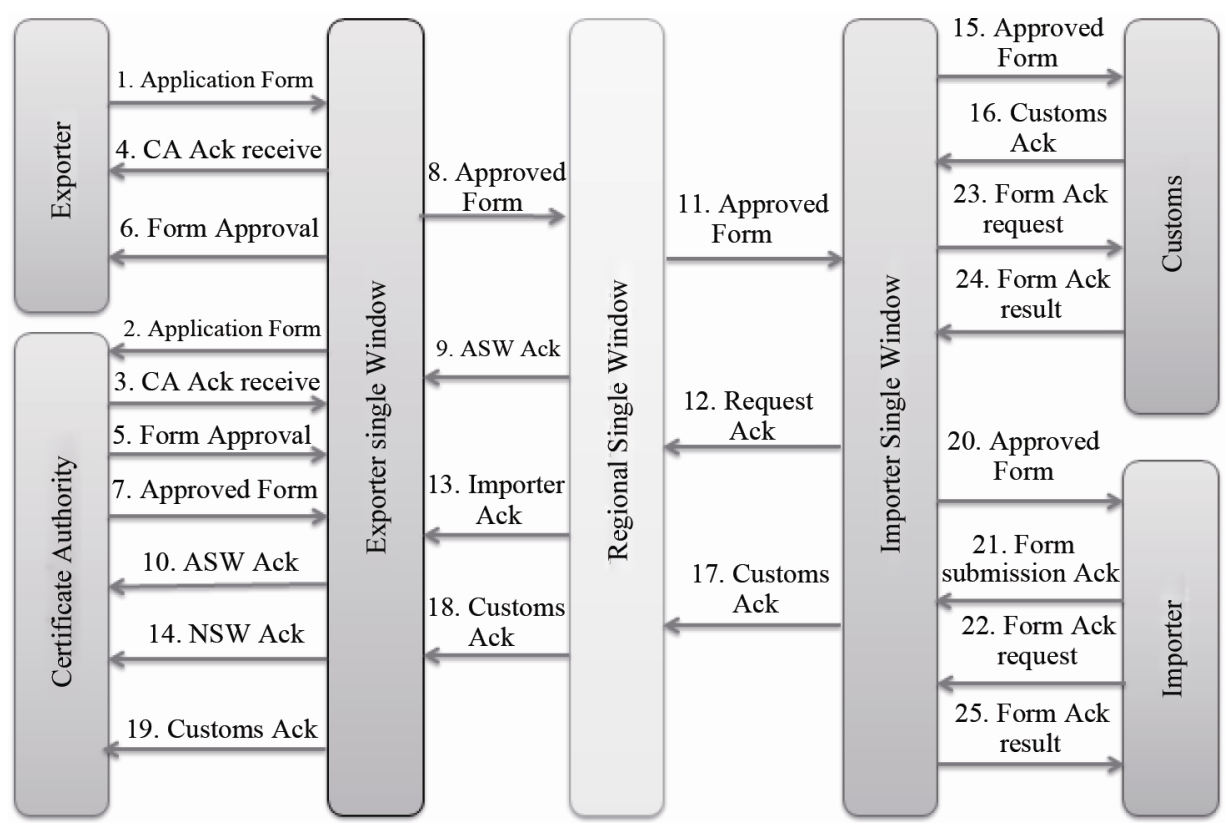

Figure 6. Document exchange in the content layer.

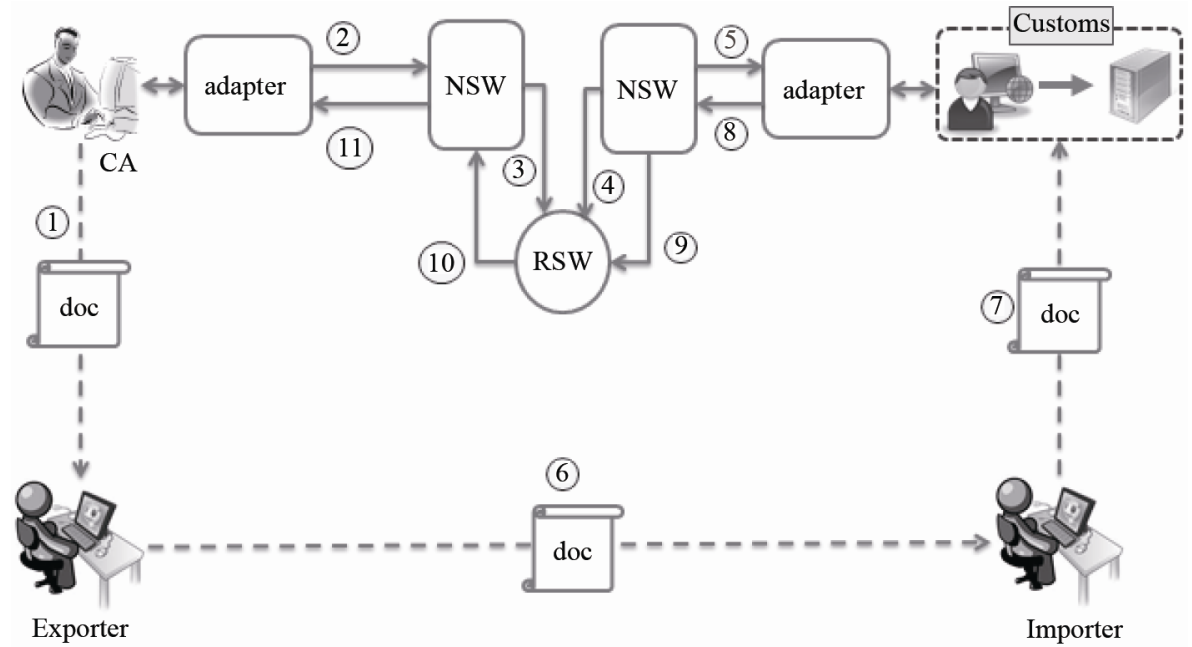

Figure 7. Certification authority scenario in the model.

adapters are needed in each side of the supply chain to change the format of data elements into a readable format. This specification of cross-border models besides using web services as a communication solution makes the suggested model more portable and independent of different platforms. Implementation itself can be analyzed through different layers. The closest layer to user is user interface layer which is known as web based interface and in the database layers the data exchange is done according to all the points, which was mentioned before about establishing a cross-border data exchange in a B2B e-commerce system (Figure 8).

\section{A Sample Process Analysis}

In this section the verification of the suggested model is done according to a four phased scenario. In this scenario a communication between two trade points over borders, and the role of each of the model components are being discussed. These four phases are:

Phase 1: Exporter sign in to system and application record.

Phase 2: Interaction between exporter and exporter national single window.

Phase 3: Interaction between exporter and importer single windows.

Phase 4: Interaction between importer and importer single window.

Now, the above phases through each of the following subsections are discussed. In each subsection, the func- 


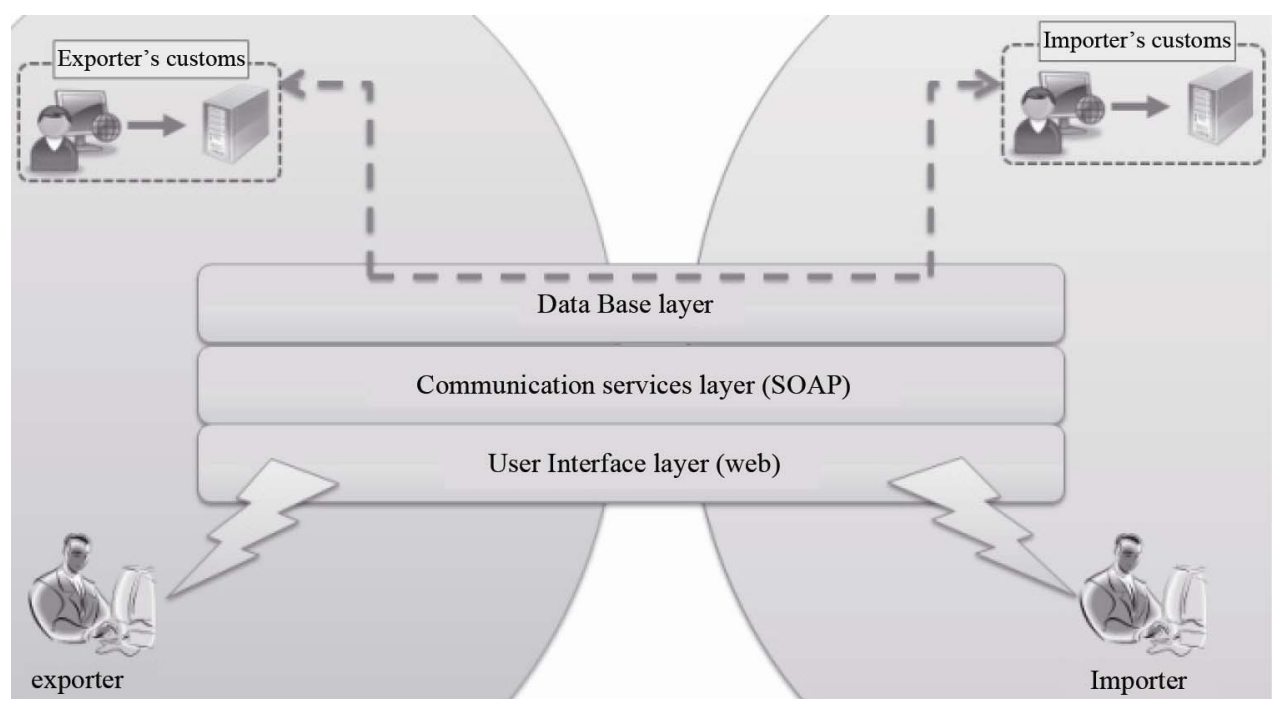

Figure 8. Model implementation schema.

tionality of each component in the cross-border model was discussed according to the schemas of messaging and content layers (Figures $\mathbf{7}$ and $\mathbf{8}$ ).

\subsection{Phase 1: Exporter Sign in to System and Application Record}

In this phase the exporter and CA center are the main actors of the scenario. The significant target is to record a successful sign in for the exporter in the national single window system. So, the exporter can go through next steps in the future phases.

The detailed interactions between the model's components include sending application form to sign in and receiving the CA approval. The exporter sends his request to start a transaction to the national single window. To record the sign in process, national single window asks the CA component for approval, and after receiving the approval message the transaction is being acceptable as a valid export process [15]. It should be considered that in each step of the scenario the communication between actors like exporter, importer and CA are done by the single window component (Figure 9).

After this phase the electronic record of the export transaction will be saved and kept to use in the next phase which is the interaction between exporter and exporter national single window (Figure 10).

\subsection{Phase 2: Interaction between Exporter and Exporter National Single Window}

In the second phase of the scenario, main actors are exporter and CA center, but there are more components involved in this part of the process. The perquisites of this phase are about having a connection with the national single window and being able to send and receive

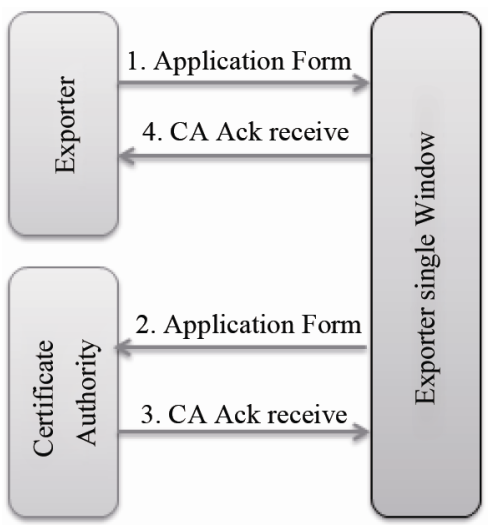

Figure 9. Exporter sign in, content layer.

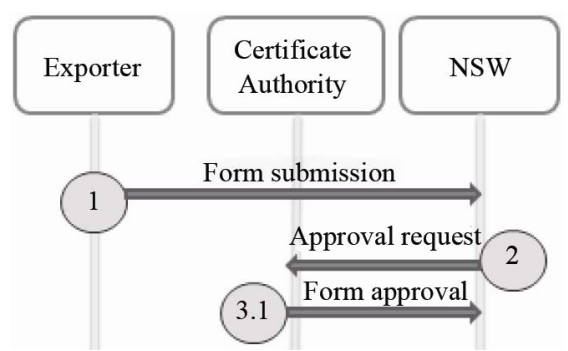

Figure 10. Exporter sign in, messaging layer.

forms and messages.

The validity of the form's signature is being approved by the CA in the national and regional levels based on exporter's private key (Figure 11).

Each single message or document which is being sent through the layers of model must be checked by the regional single window. In the messaging scenario, the approval message is sent to the regional single window to be validated over regional regulations and after that the regional approval is sent back to the exporter as an ap- 
proval of continuing the process.

In other words, the national single window is making the chain of communication complete while the regional single window is having supervision due to regulations.

After receiving the regional approval, the last status of the form is being changed to "approved". This shows that the process can go on to the thirds phase which is interaction between exporter and importer single windows (Figure 12).

\subsection{Phase 3: Interaction between Exporter and Importer Single Windows}

The third phase is about Interaction between exporter and importer single window, main actors are CA center and customs of importer. Every document or its approval must be sent through national singles windows and regional single window. Like the second phase each component is responsible for either forwarding or approving the forms. As the importer side is being discussed here the customs is one of the main actors which have to approve the form as declaration process (Figure 13).

In the third phase of the scenario in the messaging layer, at last the approval of the form received is sent from customs to the CA center in the side of exporter. As the regional single window sends the approval to importers country, the national single window asks the customs for declaration through a form approval request.

This request is being responded by the customs as an approval message and the result will be sent to the CA

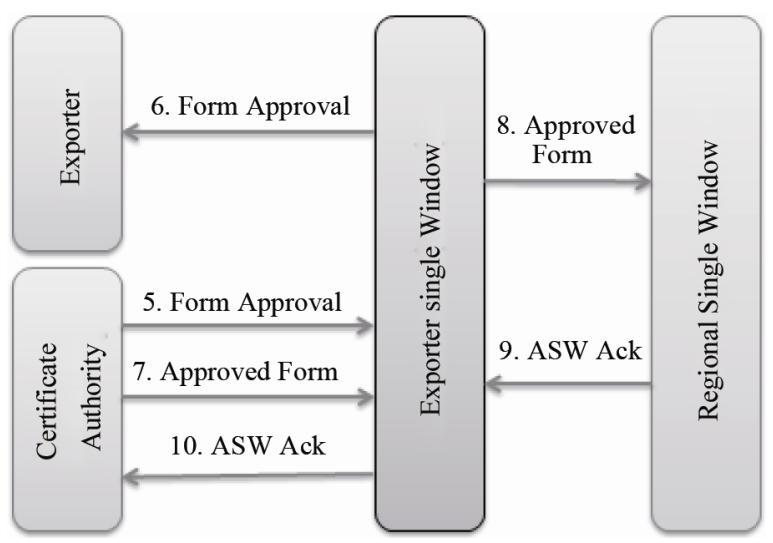

Figure 11. Exporter and NSW content layer.

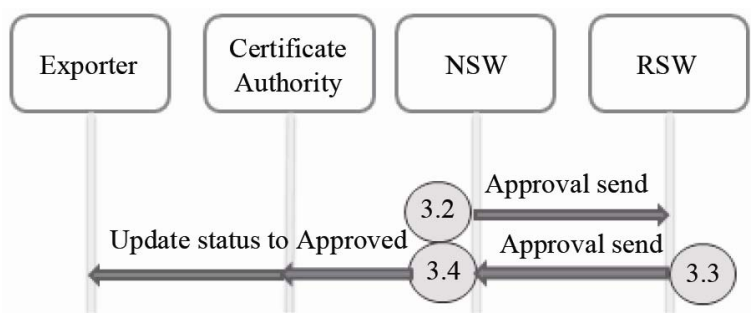

Figure 12. Exporter and NSW, messaging layer.

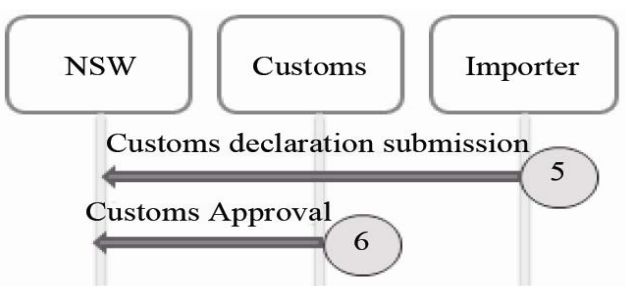

Figure 13. Importer and NSW interaction, messaging layer.

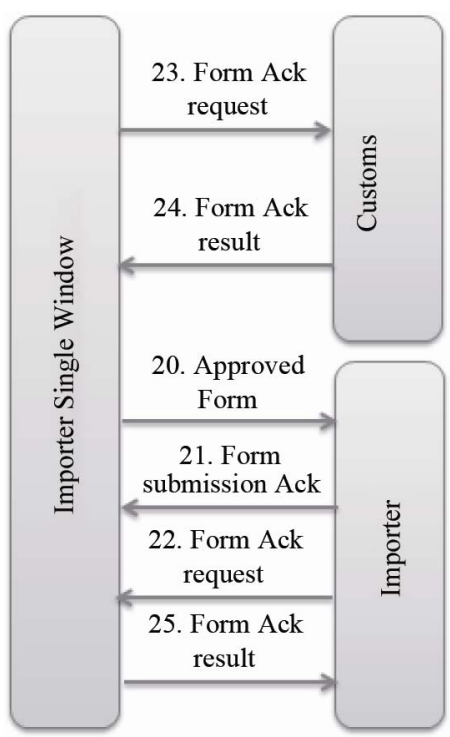

Figure 14. Importer and NSW interaction, content layer.

component of the exporter's country (Figure 15).

When the CA receives the approval message from customs of importer country, the next phase starts which is Interaction between importer and importer single window.

\subsection{Phase 4: Interaction between Importer and Importer Single Window}

In the fourth phase Interaction between importer and importer single window are discussed. The main actors of this phase are importer and customs. Importer and customs are connected to each other via national single window of the importer.

After this phase the importer must be able to receive the final approval from its customs. But it is clear that again the relation between the customs and importer is being applied through importer national single window (Figure 14).

The final approval of the form in this phase is sent to the CA center of the exporter through the single windows in national and regional levels. As the result, a sample transaction between the exporter and importer end points in the supply chain, and the functionality of each component of the cross-border model in the content and messaging layers was discussed (Figure 15). 


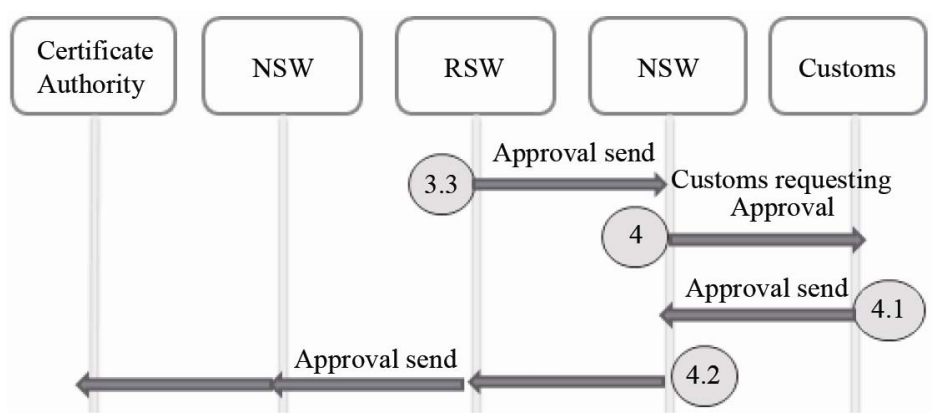

Figure 15. Exporter and importer interaction, messaging layer.

By the end of this phase, customs and importer are sending the approval of a successful process to the national single window. If according to the regulation, the CA needs this final approval to be recorded in a file, this message can be sent to the CA of the exporter to be stored.

\section{Conclusions}

In this paper after having a look at B2B e-commerce in Iran, a new localized cross-border e-commerce model based on single window concept was introduced. This model can be implemented to carry out B2B transactions over borders and presented as a roadmap trough establishing a national single window in Iran. This can be a step though joining Iran to regional single windows in future steps.

One of the key benefits of this model is that it can be implemented on UNLK format. Many of the trade partner countries today use this layout to align their paper and electronic forms, so they can exchange documents in paper and even electronic PDF format [16]. The completion guidelines released by United Nations trade facilitation center will help merchants and customs to fill and check the forms easily. Forms that designed based on UNedocs data model are in the international format, so the forms of the content layer in the suggested model can be exchanged internationally. UNedocs is a project based on UML, so that trading roles can be mapped by data modelers easily. The forms of this model can be made by tools like InfoPath and can be sent by emails $[17,18]$. Based on XML, the forms are easy to adopt and better delivery services make it easy to integrate the information in the single windows. Every part of the localization is based on best practices in the Asia region which makes the model more compatible with trading partners. The layered structure of the suggested localized model makes it more Simple, Extensible and flexible as a model to implement electronic document management in Iran's trading system or any other countries by similar trading systems.

\section{Acknowledgements}

The authors would like to thank Research Institute for ICT for their support of e-commerce lab established by 2010, at Tarbiat Modares University.

\section{REFERENCES}

[1] B. Medjahed, et al., "Business to Business Interactions: Issues and Enabling Technologies,” The International Journal on Very Large Data Bases, Vol. 12, No. 1, 2003. pp. 59-85. doi:10.1007/s00778-003-0087-z

[2] United Nations Center for Trade Facilitation and Electronic Business, "Facilitation Measures Related to International Trade Resources,” 2008.

[3] S. Keretho, “'Single-Window E-Logistics’: Policy Initiatives and Projects in Thailand," UNECE/UNESCAP Workshop on UNedocs for Single Window Facilities in Asia and the Pacific, Bangkok, 10-14 December 2007.

[4] M. Misovicova, "Single Window Overview and Best Practices,” Singapore-ADB CAREC/ATRIUM Forum on Trade Facilitation, 2008.

[5] United Nations Center for Trade Facilitation and Electronic Business, "Buy Ship Pay Modeling Guidelines,” 2008.

[6] United Nations Center for Trade Facilitation and Electronic Business, “The Harmonized Data Model Buy Ship Pay Subset for International Trade,” 2008.

[7] I. Kabak and A. Dogac, "A Survay and Analisys of Electronic Business Document Standards,” Vol. 42, No. 3, 2008, Article ID: 11.

[8] United Nations Economic and Social Committee for Asia and Pacific, "ESCAP Trade Facilitation Framework," 2004.

[9] A. Grainger, "Customs and Trade Facilitation: From Concepts to Implementation,” World Customs Journal, Vol. 2, No. 1, 2008, pp. 17-30.

[10] Trust Fund for Trade Facilitation and Negotiations, "The Electronic Submission of Trade Documentation,” 2006.

[11] S. Probert, "A Roadmap for Implementation of UNedocs," SPECA-ASEAN Capacity Building Workshop on Trade Facilitation, 2007.

[12] S. Lim, "Cross-Border Data Exchange in the Asia Pacific Region: Current Status and Future Directions,” UNECE/ UNESCAP Workshop on UNedocs for Single Window Fa- 
cilities in Asia and the Pacific, Bangkok, 10 December 2007.

[13] H. C. Moon, S. R. Shing and D. Y. Kim, "Issues in the International Standards of Electronic Documents for Global E-Trade," Proceedings of the International Conference on Social Science, Economics and Art, Kuala Lumpur, 14-15 January 2011, pp. 164-168.

[14] M. Pikart, "UNCEFACT Framework of Standards for Paperless Trade,” ESCWA Regional Workshop, Cairo, 2007.

[15] United Nations Center for Trade Facilitation and Elec- tronic Business, “A Roadmap towards Paperless Trade,” 2006.

[16] T. Phuaphanthong, "APEC Data Harmonization toward Single Window Paperless Environment,” APEC Endorsed Project, 2009.

[17] M. Dill, "UNedocs Extended Module for Integrated Data Exchange at Border Crossing," UNECE/UNESCAP UNedocs Workshop on Trade Facilitation, 2007.

[18] P. Stokes, "Single Window Experiences," UNECE Workshop on United Nations Electronic Documents, 2007. 